\title{
Subjetivação e Processos de Identificação. Sujeitos e Línguas em Práticas Discursivas - Inflexões no Ensino
}

\author{
Matheus França Ragievicz ${ }^{1}$
}

Gestos de leitura postos em trânsito sob o prisma de capítulos alinhados em torno da temática que toca num posto caro aos estudiosos da linguagem e do discurso: a(s) língua(s) e suas relações possíveis com o ensino. Nesta direção caminha o livro organizado por Maria Onice Payer e María Teresa Celada (2016), cuja trajetória intelectual e contribuições ao estudo da língua - materna e estrangeira - repercute nas bordas e centros dos onze artigos que acompanham o exemplar Subjetivação e Processos de Identificação. Sujeitos e Línguas em Práticas Discursivas - Inflexões no Ensino, publicado pela Pontes Editores em 2016.

O livro surge como fruto de esforços do Grupo de Trabalho (GT) em Análise de Discurso, no interior da Associação Nacional de Pós-Graduação em Letras e Linguística - ANPOLL, mais especificamente, da linha de investigação do GT, Subjetivação e Processos de Identificação. Parte dos objetivos de atuação da frente consistia na promoção e na divulgação de trabalhos relacionados à referida temática. Desta forma, frequentando um lugar em que o dizer é afetado pelos estudos do discurso, os autores lançam luz sobre a constituição do sujeito (aprendiz) de língua(s), numa interface entre os Estudos da Linguagem e as contribuições da Análise de Discurso. As afinidades teóricas e de interesses comuns atravessam os diferentes textos, oferecendo uma interlocução afinada quanto ao processo de produção de sentidos. Evocando Pêcheux (1975), para quem interpelação, identificação e produção de sentidos se enlaçam num mesmo processo, falar em subjetivação é vislumbrar tais aspectos funcionando em conjunto, nem sempre amistosamente, seja em relação ao simbólico ou ao político. Instaurando outras cenas, damos lugar àqueles que merecem nossa escuta.

Maria Onice Payer e María Teresa Celada iniciam a série de capítulos do livro com o texto intitulado Sobre sujeitos, lingua(s), ensino. Notas para uma agenda. Nele, as autoras demonstram como a análise de discurso pode contribuir para pensar o ensino para além da aplicação, transposição e execução de artefatos teóricos do universo didático. A escrita do texto reflete conceitos que foram ganhando forma e força ao longo da trajetória das autoras; a importância de pensar a memória em relação à língua, assim como as margens das condições do ensino e da presença do espanhol, são exemplos presentes e indícios de uma reflexão que não cede às modas teóricas, que encontra no lugar da análise de discurso, um lugar para problematizar contundentemente o ensino de línguas, a memória de língua e, por consequência, o real da língua.

Texto difícil de ser sintetizado e apresentado ao leitor em palavras que se acerquem minimamente aos gestos analíticos postos em contato; ressalta-se a conjugação entre produção de saber e ensino, a posição de identificação dos sujeitos na inscrição ao simbólico, a refutação da subordinação ao discurso pedagógico, assim como da análise do discurso em relação à língua e ao ensino de línguas. Reflexões amadurecidas que são tecidas num grau de aprofundamento do saber que não permite atalhos; por isso, resta nossa sugestão ao leitor: a leitura na íntegra do texto e a não redenção aos relances que aqui se inscrevem.

1 Mestrando em Estudos Linguísticos pelo PPGL/UFPR. 
Na sequência, temos o texto Composições Musicais Brasileiras: Discursos sobre a Língua de autoria de Eliana de Almeida e Thalita Sampaio. As autoras realizam um instigante trabalho em relação à materialidade da língua: demonstram, através de canções, o encontro de línguas que passam a significar e a compor o sentido num tênue pêndulo, pelo deslizamento. A poesia, defendida como constitutiva da língua, perfaz os encontros, a sonoridade, o efeito nas canções; efeito que sempre se faz sentir a partir da relação da língua com a história. Mobilizando as canções Não tem tradução, Cem mil-réis de Noel Rosa, Joana francesa de Chico Buarque, Samba do Aproach e Babylon de Zeca Baleiro, analisam tacitamente como o contato entre diferentes línguas (português-francês/ português-inglês), fazem ecoar sentidos sobre a materialidade linguística, implicando formas de identificação dos sujeitos.

As autoras destacam o papel da metáfora, seus efeitos e ressonâncias intrínsecos à língua, assim como o movimento da incompletude, que permitem que o jogo da polissemia engendre nas canções. $\mathrm{Na}$ articulação do português com as outras línguas, por meio de um gesto de interpretação, Almeida e Sampaio mostram como diferentes memórias se entrelaçam e passam a produzir sentidos no contato do linguístico. Numa reflexão sobre a(s) língua(s) enlaçada à poesia, as autoras realocam esta última num lugar privilegiado, por vezes negligenciado nos trabalhos sobre a língua, destacando seu papel de constitutividade na linguagem.

Em Algo fala antes nos discursos de estudantes sobre língua(s) e tradução dividem a autoria Solange Mittmann, Gláucia da Silva Henge, Michele Teixeira Passini e Laís Virginia Alves Medeiros. As autoras colocam em causa o funcionamento da língua e o imaginário sobre tradução, ancorando-se na Análise de Discurso. No trabalho de composição dos dados, encontramos pistas interessantes para constituição de instrumentos que permitam o acesso ao discurso dos sujeitos, sem que o que fale antes seja marcado preponderantemente pelo imaginário de o que o pesquisador espera que eu responda. As sequências discursivas analisadas compõem um arquivo de respostas de alunos de um curso superior de bacharelado em Letras, com ênfase em tradução.

Ao mobilizarem diferentes sequências, as autoras chamam atenção para o imaginário de língua, especialmente, o apagamento e a isenção do outro (tradutor) na alteridade constitutiva do gesto de traduzir. Os fatos discursivos ${ }^{2}$ também exprimem um flerte perigoso com a noção de literalidade ${ }^{3}$, uma vez que enquanto alunos de tradução isso aponta para uma não penetração de discussões fundamentais à atividade de tradução e suas consequentes implicações práticas, resultando na sustentação do imaginário já bem conhecido e difundido sobre a língua no ato de tradução: a língua da comunicação sem empecilhos, uma Babel anunciada! Por isso, a opção das autoras é contundente: defendem teorias como análise do discurso na formação do tradutor, a fim de abalar esse imaginário já-dado.

2 Salientamos que no trabalho do analista de discurso entendemos que o gesto analítico dá-se em relação a fatos discursivos, isto é, não se parte do empirismo, nem do arquivo como um todo; operacionalizam-se recortes que originam as sequências discursivas, instâncias em que se pode, através do gesto de interpretação, chegar ao funcionamento do discurso. Desta forma, as sequências discursivas também podem ser entendidas como fatos do discurso, uma vez que o que está em causa no trabalho do analista não são os dados, mas os fatos de linguagem e, por consequência, fatos do discurso.

3 Fazemos aqui, uma crítica declarada à noção de literalidade. Se a levarmos a sério, veríamos a língua diretamente colada à coisa, pensamento e linguagem ligados por uma simples ignição, os sentidos sempre se compondo à naturalização; desta forma, apaga-se a história, os jogos de força e a ideologia. Censura-se o fato que o sentido pode tornar-se outro e ainda mais: que a luta de classes não produz nenhum efeito nos processos de significação. 
Carolina Fedatto, em $O$ que se diz ao negar-se a ler?, nos fornece significativos subsídios para refletirmos sobre o ato de negar-se a ler, tecido a partir de um diálogo sutil entre Psicanálise e Análise de Discurso. Para tanto, baliza os sentidos de leitura, formulando uma associação ao conceito de letra, advindo da teoria psicanalítica. A autora assume, desta forma, que a conexão entre leitura e escrita, longe de ser equitativa ou distinta, é desigual, isto é, o valor atribuído à leitura coexiste em dependência da valoração da escrita, tida como meio para cultivo da língua e seus elementos sonoros.

Compondo o mote de análise, Fedatto vale-se de campanhas publicitárias de incentivo à leitura, de dados estatísticos e do filme Minhas tardes com Margueritte (La tête en friche) do diretor Jean Becker. A partir das análises são tecidas algumas considerações sobre o ato de (negar-se a) ler, considerando que os discursos difundidos sobre a leitura colaboram para o enrijecimento da posição-sujeito leitor, que acabam não coadunando com a sua efetiva prática. Nessa direção, negar-se a ler é colocar-se como mau sujeito diante dos dizeres hegemônicos sobre a leitura e sua fundamental presença na vida dos sujeitos. Ao negar-se a ler, especula a autora, os sujeitos vislumbram que a prática de leitura é uma prática entre outras; assim, o trabalho deixa à vista os (des)enlaces entre saberes que sustentam o imaginário social e a interpelação do sujeito à leitura, desmontando as evidências de que a leitura produz intervenções e transformações imediatas, irrecusáveis, absolutas no corpo social.

Águeda Aparecida da Cruz Borges, em Sujeito/espaço/língua e memória: relações históricas, lança-se a refletir os efeitos da relação entre a língua Xavante e a memória da língua nacional/língua portuguesa. A autora atesta diferentes forças que se (re)introduzem e sustentam a circulação de sentidos no interior da língua indígena. Também demonstra os processos que cercam a constituição da língua Xavante e, por consequência, os processos de subjetivação correlatos a ela. No trabalho, a autora deixa visíveis os requintes de crueldade que predominam nas ações orquestradas de assassinato das línguas indígenas, principalmente, no apagamento que as políticas nacionalistas e neoliberais promovem em relação à língua, à cultura e à tradição indígena.

Para compor o panorama de análise, Borges vale-se de mapas, notícias, relatos dos indígenas, quadros comparativos entre as línguas Xavantes e o português, demonstrando como as línguas Xavantes, em especial, o macro-jê (língua falada pelos indígenas dos relatos) produz efeitos diferentes no ato de nomeação quando é tocado pelo português e pela memória nacional. Há, nas palavras da autora, um atravessamento latente de discursos outros nas sequências discursivas analisadas, mostrando que é preciso olhar a língua e os processos de subjetivação em relação à história, à memória, ao espaço e às condições de produção. Nesse trabalho, Borges desvela modos de resistência dos indígenas, constantemente espoliados do seu próprio lugar, buscando margens para assentarem-se.

Na continuação, temos A escrita e sujeitos-professores: relações, cicatrizes, ensino e identidades profissionais de Filomena Elaine P. Assolini, que busca compreender como a prática docente e a identidade profissional docente são atravessadas por memórias do processo de formação dos docentes na educação básica. As sequências analisadas denotam experiências decisivas dos sujeitos-professores na relação com a escrita, na reafirmação de saberes já-sedimentados sobre esta prática, marcando movimentos de reafirmação do discurso pedagógico autoritário. Funcionam, nas falas, pré-construídos sobre o ato da tessitura textual, que atravessam a opacidade, a literalidade e a passividade do sujeito. O trabalho mostra-se significativo na medida em que o gesto de interpretação que imbrica a teoria e a análise consegue desmontar as evidências naturalizadas desses 
dizeres; nesse movimento, descortina como memórias anteriores à formação universitária também constitui a prática docente, defendendo que esta dimensão deve ser tomada como questão de formação.

No capítulo Emergências subjetivas no processo de ensino-aprendizagem de língua estrangeira, de Juliana Santana Cavallari, percebemos o desvelo e primor teórico, na articulação entre Análise de Discurso e Psicanálise. Apesar de o diálogo fluir com maior nitidez junto à teoria psicanalítica, a autora faz trabalhar noções nodais que servem de iniciador aos leitores com menos traquejo com a temática, especialmente nas associações ao ensino de língua inglesa. Da psicanálise, Cavallari problematiza o discurso do mestre e o discurso analítico, formulados por Lacan, buscando margens para estender as implicações desses discursos à educação. Enquanto o primeiro é refutado e associado ao discurso didático, o segundo é talhado com vistas a pensar o ato educativo como possibilidade de entrelaçamento entre as margens da subjetividade e a impossibilidade mesma do gesto de educar.

São tomados como objetos de análise passagens de situações ocorridas em aulas particulares e individuais de língua inglesa, ministradas pela própria autora, que contornaram o equívoco. Essas situações que, diante de outras perspectivas seriam restos, simples erros, são trabalhadas como horizontes possíveis, condições de emergência da própria subjetividade que se entrelaça à língua. Ao tocar no equívoco, os sujeitos possibilitam a enunciação da própria subjetividade e caminhos para transformações pessoais, aberturas. Desta forma, a autora demonstra como a escuta e a consideração do equívoco, numa atividade corriqueira de ensino de língua inglesa, podem produzir elementos significativos à aprendizagem e aos aprendizes.

Já em A formação do aluno monitor em contexto colaborativo, de Joelma Pereira de Faria, temos uma revisão do papel da atividade de monitoria e da função do próprio monitor. Comum em práticas universitárias, a monitoria é ofertada, usualmente, em horário contrário às aulas, como auxílio pontual a dificuldades de aprendizagem de determinado conteúdo. Esse modelo, como aponta Faria, contempla diversas falhas: de formação do monitor, ausência de um professor supervisor e pouca possibilidade de participação dos alunos na atividade de monitoria. Desta forma, Faria estabelece diálogos com Faria (2003), que sustenta outro modelo de monitoria, o qual contemple a formação do monitor, a presença do professor e a participação dos alunos, num movimento de aprendizagem colaborativa em sala de aula. Faria busca, ao longo do texto, estender essa discussão para o ambiente escolar, defendendo o papel do aluno monitor como mediador, numa prática colaborativa entre professor - monitor - alunos.

A autora orienta sua reflexão nos pressupostos da psicologia Vygostkyana, a fim de exibir o processo de aprendizagem em perspectiva mais ampla, para então denotar o papel e as ações que cada agente do processo de ensino-aprendizagem deve orquestrar, seja o aluno, o professor, a escola ou o monitor. Faria é enfática ao defender que esse canal de trocas e diálogo deve ser marcado pela possibilidade de renegociações e reconstruções das atividades traçadas, possibilitando margens e outras perspectivas para o trabalho pedagógico na escola e na universidade enquanto construção sócio-histórica.

Na sequência, em Processos de identificação do professor e do aluno com o discurso pedagógico: repensando as práticas de leitura e escrita na escola, cuja autoria é dividida entre Silvia Regina Nunes e Cleiton de Souza Sales, são tecidas reflexões a respeito do ensino de língua portuguesa, a partir de uma intervenção pedagógica. Algumas contribuições da Análise de Discurso mostraram-se preponderantes, sobretudo, àquelas relacionadas 
ao gesto de autoria e ao discurso pedagógico. Na composição da cena de análise, além do relato de condução das atividades, realizadas no escopo do ensino fundamental, os processos de identificação da posição-sujeito professor são esquadrinhados em relação aos documentos oficiais de ensino.

Os autores defendem que o discurso pedagógico corporifica-se nos documentos oficiais e ressoa como interdição na formulação de trabalhos alternativos de autoria e de leitura. Sendo assim, colocam-se a favor de atividades que possibilitem os alunos constituírem a autoria e inserirem-se na dinâmica do processo escolar, como protagonistas do que seus dizeres. $\mathrm{O}$ texto é tecido com cuidado: a relação entre as análises dos documentos e os pressupostos da teoria do discurso fluem em consonância, intrincados mutuamente; isso demonstra o cuidado da reflexão sobre o/do ensino de língua portuguesa a partir de um fazer teórico responsável.

Beatriz Maria Eckert-Hoff, autora de Língua, memória, imigração: errâncias e travessias em relatos de cartas, realiza significativamente o trabalho de, inscrita na Análise de Discurso, demonstrar o funcionamento da língua no atravessamento com memórias de imigração alemã materializadas em cartas. Os recortes selecionados para análise emergem de diferentes condições de produção, que se fazem marcar em palavras que marcham para a deriva, na possibilidade da significação encontrar no diferente um espaço de cultivo. Os sujeitos que se colocam na posição de autoria das cartas são imigrantes alemães que escrevem para seus familiares, que ficaram na Alemanha.

O trabalho de análise empreendido permitiu descortinar questões que atravessam as diferentes falas dos imigrantes, revelando sentimentos da migração, gestos de identificação com a língua, com os dizeres sobre a nação, projeções de imaginários postos em jogo. Esse movimento na relação língua - sujeito nos mostra os diferentes modos de consumação do processo de subjetivação, como eles se afetam mutuamente. A autora consegue mobilizar diferentes considerações na relação entre os fatos e a teoria, fazendo intervir uma prática analítica que demonstra a constitutividade da subjetividade na formulação de diferentes dizeres nas cartas dos imigrantes.

Partindo de um enlace entre Análise de Discurso, História das Ideias Linguísticas e Semântica do Acontecimento, Leandro Rodrigues Alves Diniz, em Políticas de Línguas no Instituto Machado de Assis: a formulação e o abandono de um projeto, explora diferentes materialidades significantes (notícia, entrevista, portal on-line) a fim de sinalizar os processos discursivos que encapam a criação do Instituto Machado de Assis e seu duvidoso abandono. Para sustentar sua posição mobiliza conceitos como espaço de enunciação, de Guimarães (2002), no qual adensa os efeitos da sobreposição entre língua oficial, nacional e materna, que estruturam o espaço de enunciação sobre a língua em solo brasileiro.

As sucessões de fatos, de iniciativas e de procedentes que perpassam as diferentes fases de formulação do instituto transbordam num claro confronto entre forças políticas a nível nacional e internacional, assentando-se em contradições que se inscrevem e ecoam por e a partir da dimensão dos processos históricos e de identificação com a língua portuguesa no Brasil. O autor assevera uma hipótese sobre os equívocos de formulação do instituto e sua não-implementação, demonstrando como a enunciação da língua portuguesa ancora-se em derivas e memórias que materializam saberes da colonização. Sendo assim, na formulação, o projeto ganha contornos menos visíveis, mas igualmente presentes ao relacionar-se intimamente à lógica mercadológica, ao nacionalismo e ao silenciamento do outro. 


\section{Conexão Letras}

Em vias finais, colocamos em evidência o significante do título - inflexão. O que está em causa numa inflexão no ensino? Certamente, não se trata de transformações, mudanças, receitas ou modelos ditados de reflexão que englobam o ensino. Trata-se, sim, de cultivar a possibilidade de vislumbrar outro caminho no trabalho com a língua, com a sensibilidade que toca a significação na relação de identidade, de alteridade do sujeito no simbólico. Os textos selecionados caminham nessa direção: mostras de pontos de fuga, de deriva, de incompletude, de deslizamento da língua, inscrita na história e constituída pela memória. Com isso, é acertado que os processos de subjetivação configuram vias que possibilitam a movência dos sujeitos em redes de filiação históricas, que hoje se encontram atreladas às transformações tecnológicas, às formas mais refinadas e sofisticadas de controle social, ao capitalismo em estado avançado e suas faces sombrias e capciosas - retomando, em certa medida, o argumento de Maria Onice Payer e María Teresa Celada. Os efeitos dessa relação ressoam, tomam forma, corpo; é a especificidade da relação entre sujeito e simbólico que (re)organiza as identidades, as línguas, os lugares de ancoragem de dizer no rito de subjetivação, iniciação eterna ao significante marcada pela história e pelo político.

\section{Referências}

FARIA, J. P. de. A monitoria como prática colaborativa na universidade. (Dissertação de Mestrado). Programa de Pós-graduação em Linguística Aplicada e Ensino de Línguas. Pontifícia Universidade Católica de São Paulo, 2003.

GUIMARÃES, E. Semântica do acontecimento: um estudo enunciativo da designação. Campinas: Pontes, 2002.

PAYER, M. O.; CELADA, M. T. (Org.). Subjetivação e Processos de Identificação. Sujeitos e línguas em práticas discursivas - inflexões no ensino. Campinas: Pontes Editores, 2016.

PÊCHEUX, M. Semântica e discurso: uma crítica à afirmação do óbvio. 5. ed. Campinas: Editora da Unicamp, 2014 [1975]. 